\title{
Fallecimiento del señor V. H. Umbricht, miembro honorario del CICR
}

El pasado 14 de julio de 1988, el CICR recibió con profunda tristeza la noticia del fallecimiento, tras una larga enfermedad, del señor Victor H. Umbricht, miembro honorario y ex vicepresidente del CICR.

El señor Umbricht, elegido miembro del CICR en 1970, fue miembro y vicepresidente del Consejo Ejecutivo desde 1973 y, más tarde, vicepresidente del CICR hasta 1985, así como miembro honorario del mismo a partir de 1986. Durante casi veinte años, marcó, con su personalidad y sus realizaciones, los profundos cambios de la Institución.

Nacido en Endingen (Suiza), el año 1915, el señor Umbricht era doctor en derecho internacional por la Universidad de Berna. Tras prestar servicio, de 1941 a 1953, en el cuerpo diplomático suizo, ingresó en el Banco Mundial (Washington) como director adjunto de las operaciones para Europa, África, Asia y Australasia. En 1957, fue nombrado director general de la Administración Federal de Finanzas, en Berna. De 1960 a 1961, fue asesor financiero y presidente del Consejo Monetario de Kinshasa (ex Congo belga) y, de 1965 a 1985, miembro del Consejo de Administración de las sociedades CIBA y CIBA-GEIGY de Basilea. De 1968 a 1976, bajo los auspicios de la ONU, fue miembro del Consejo Consultivo del Comité del Mekong (organización económica para el desarrollo económico de la cuenca del Mekong, que comprendía Camboya, Laos, Tailandia y Vietnam).

Al servicio del CICR, participó en numerosas misiones en las zonas más conflictivas del mundo: en Oriente Medio, durante la guerra de octubre de 1973; en el sudeste asiático, durante las guerras de Vietnam y de Camboya; en Bangladesh, durante la guerra de independencia y, en Uganda, durante los sangrientos disturbios internos.

Como mediador de las Naciones Unidas para la Comunidad de África oriental, de 1977 a 1984, el señor Umbricht logró resolver el litigio entre Kenia, Uganda y Tanzania, granjeándose así la confianza de las partes concernidas. 
De la exceptional capacidad del señor Umbricht como mediador e intermediario internacional se beneficiaron tanto el Movimiento de la Cruz Roja y su objetivo específico de ayuda y protección a las víctimas de las guerras como los millones de hombres y mujeres en cuyo favor intervino infatigablemente en el mundo entero.

Al rendir homenaje a la memoria del señor Victor H. Umbricht, el presidente del CICR, señor Cornelio Sommaruga, declaró: «Victor Umbrecht se consagró a la causa de la Cruz Roja con un optimismo inquebrantable, una inconmovible energía y una abnegación infatigable... Victor Umbricht, verdadero ciudadano del mundo, no se contentó con ser un simple miembro; se identificó totalmente con los objetivos del CICR y quiso también que nuestra Institución se mantuviera fiel a sus principios de competencia absoluta, de no-formalismo, de discreta modestia y de tolerancia sin paternalismo... Sus objetivos y anhelos siguen siendo los nuestros. Le estamos profundamente agradecidos por habernos servido de ejemplo,... y estamos impregnados de su modelo».

\section{Fallecimiento del profesor D. Frei, miembro del CICR}

El profesor Daniel Frei, miembro del Comité Internacional de la Cruz Roja desde el 1 de marzo de 1986, falleció repentinamente el 1 de agosto de 1988.

Nacido el 24 de octubre de 1940 en San Gall, Daniel Frei era doctor en Historia por la Universidad de Zurich a los 24 años. Prosiguió sus estudios en la «London School of Economics and Political Science», y después en la Universidad de Michigan y, en 1967, se diplomó en el Instituto Universitario de Altos Estudios Internacionales de Ginebra.

En 1968, fue nombrado profesor asociado y, en 1971, profesor ordinario de Ciencias Políticas en la Universidad de Zurich, donde también dirigió el Instituto Suizo de Investigaciones Internacionales.

Daniel Frei es autor de numerosas publicaciones sobre las relaciones este-oeste, el desarme, la neutralidad y la cooperación internacional. Era miembro del Club de Roma y asesor del UNITAR (Instituto de las Naciones Unidas para la Formación Profesional y la Investigación) 